\title{
Estimation of changes in genetic parameters in selected lines of mice using REML with an animal model. 2. Body weight, body composition and litter size
}

\author{
B. K. BENIWAL, ${ }^{*} \ddagger$ I. M. HASTINGS, ${ }^{*}$ R. THOMPSON $\dagger \&$ W. G. HILL*§ \\ *Institute of Cell, Animal and Population Biology, University of Edinburgh, West Mains Road, Edinburgh EH9 3JT and \\ TARFC Institute of Animal Physiology and Genetics Research, Edinburgh Research Station, Roslin, Midlothian \\ EH25 9PS, Scotland
}

\begin{abstract}
Restricted Maximum Likelihood (REML) with an animal model was used to estimate genetic parameters of body weight, body consumption and litter size of lines of mice selected for 20 generations on an index of lean mass at 10 weeks in males, highly correlated with body weight, and for a further 18 generations on body weight at 10 weeks in males and females. Univariate and multivariate estimates of heritability were about 0.5 and those of common environment correlations were about 0.25 for both body weight and composition. Body weight and fat pad weight had genetic and phenotypic correlations of about 0.5 . The heritability estimate of litter size was about 0.15 from univariate analysis, rather lower from multivariate, and the estimate of its genetic correlation with body weight was about 0.25 . There were reductions in heritability of both body weight and litter size in later generations, even though full pedigrees were fitted and inferences made to the base population, but a plateau in response to selection for increased body weight could not be explained by a complete attenuation of genetic variance.
\end{abstract}

Keywords: body composition, body size, heritability, litter size, maximum likelihood, selection.

\section{Introduction}

If a population is selected for a particular trait or index of traits its heritability can be computed from the regression of offspring on parent or, equivalently, regression of response on selection differential for that trait. The equivalent regression coefficient either for another trait not directly under selection or for a component of the index does not, however, give unbiased estimates of heritability of that trait but of the ratio of genetic to phenotypic covariance. Methods such as multivariate maximum likelihood incorporating information on both the trait(s) under selection and the correlated trait are necessary to obtain unbiased estimates (Meyer \& Thompson, 1984). Restricted Maximum Likelihood (REML) with an animal model was therefore used to estimate parameters in the base

$\ddagger$ Present address: Rajasthan Agricultural University, College of Veterinary and Animal Science, Bikaner-334 001, India.

$\S$ Correspondence. population for body weight and composition in lines of mice ( $P$ lines) selected on predicted lean mass, which was an index of whole body weight and weight of a fat depot. In a previous paper (Beniwal et al., 1992) a univariate analysis was carried out on the lean mass index for the 20 generations of selection conducted for that trait; here the aim was to investigate relationships among the components of the index.

After 20 generations of selection for predicted lean mass in males, the three high and three low replicates of the $\mathrm{P}$ lines were crossed and selection was then continued for a further 18 generations using body weight in both sexes as the sole selection criterion. A total of 38 generations (i.e. $20+18$ ) of selection were therefore analysed to assess changes in genetic parameters in the later generations as there were indications that selection responses was attenuated. The REML methods using the animal model enable inferences to be traced back to the base population, assuming the infinitesimal model of very many unlinked additive genes applies, so changes in parameters imply 
failure of the model (for discussion see Beniwal et al., 1992).

The litter size for each generation was also recorded, and substantial correlated responses to selection for lean mass occurred. A further aim was to assess the relationships between traits of growth and reproduction. Multivariate maximum likelihood methods allow unbiased estimates of genetic parameters for litter size to be obtained despite the selection, and indeed use the correlated responses to increase the efficiency of the estimate. As only full sib families were available and selection was practised within families, estimates of parameters such as heritability of litter size with acceptable standard errors could be obtained only by using the whole relationship structure. The long-term nature of the experiment also enabled changes in genetic variance for litter size to be estimated.

\section{Materials and methods}

\section{Animals}

Establishment of the P-lines and results of the first 20 generations of selection for predicted lean mass $(L M)$ where $L M=B W-8 \times F W$, and $B W$ is body weight $(\mathrm{g})$ of males at 10 weeks and $F W$ the weight $(\mathrm{g})$ of their gonadal fat pads, have been described previously (Sharp et al., 1984; Hastings \& Hill, 1989; Beniwal et al., 1992). There were three replicates each with high, low and unselected control lines with selection within families on $L M$ with 16 full sib families per line for seven generations, eight families subsequently. Numbers of animals recorded for each trait are given by Beniwal et al. (1992, Table 1).

At generation 20, the mean inbreeding coefficient was 22 per cent. The three replicates within each selected line were crossed to form new unreplicated lines, designated P6, where P6 high, for example, was formed from intercrosses of all possible two-way crosses of the three high $P$ replicates. No contemporary control was subsequently maintained. Sixteen pair matings were made per generation and selection was practised within families on body weight at 10 weeks (with no correction for fat) in both males and females. Matings were made at 12 weeks of age after selection decisions were taken, whereas up to generation 20 matings were at 8 weeks of age. Generation 21 overall (generation 1 of $\mathrm{P} 6$ ) comprises the two-way crosses, and results are reported here for response up to generation 38 . The inbreeding coefficients had by then reached 22 and 25 per cent in the high and low lines, respectively, coincidentally similar to that prior to crossing the replicates at generation 20 .
Records on litter size at birth (regarded here as a trait of the dam) were taken every generation. The mated females from generations $0-19$ were sampled at random within families, those from 20-37 were selected within families on body weight. From generations 0 to 20, but not subsequently, reserve matings were set up each generation and any selected family with an extremely small litter size (1-4) was replaced by its reserve.

\section{Statistical methods}

Growth traits. All analyses were with an animal model using the derivative-free REML package of Meyer (1988). The model for traits of growth (e.g. lean mass and body weight) is described by Beniwal et al. (1992). In summary, fitted fixed effects included generations, replicates (when more than one replicate was analysed) and litter size at birth. Line effects were also fitted when previous selection data were not included, for example in analysis of P6 data alone. Random effects were additive genetic (variance $V_{\mathrm{A}}$ ), litter or common environmental $\left(V_{\mathrm{C}}\right)$ and residual error $\left(V_{\mathrm{E}}\right)$, with $h^{2}=V_{\mathrm{A}} / V_{\mathrm{P}}, c^{2}=V_{\mathrm{C}} / V_{\mathrm{P}}$ and $V_{\mathrm{P}}$ being the phenotypic variance. Different variances were fitted in individual lines or over differing periods of the experiment, using a heterogeneity of variance facility with REML (Visscher \& Thompson, 1990; Beniwal et al., 1992). Univariate analyses were undertaken of body weight data up to generation 38 and bivariate analyses of body weight and gonadal fat pad weight data up to generation 20 . These traits are the components of the index used for selection and are less correlated than, for example, predicted lean mass and body weight.

A full bivariate analysis with three random components requires a nine-dimensional likelihood search which was considered impracticable. Thus the iterative method suggested by Thompson \& Hill (1990) was used in which data are transformed to canonical variates to permit near-optimal analyses of uncorrelated traits, the transformation being based on the additive genetic and the sum of litter and environmental components. Parameters for the lean mass index were estimated from the simple linear function of its components and those for a measure of fat proportion, $F W /$ $B W$, by statistical differentiation using a Taylor series approximation.

Litter size. The same model was used for the analysis of litter size, regarded as a trait of the dam, as for traits of growth with two exceptions: litter size at birth was not fitted as a covariate and, because within family selection was practised, so that usually only one daughter of a female was subsequently bred, litter of birth $\left(c^{2}\right)$ 
effects were not fitted. A bivariate animal model analysis of litter size and lean mass up to generation 20 was undertaken using the same model for each trait as in their respective univariate analyses. The bivariate analysis incorporated a genetic covariance between the traits but not an environmental covariance, because lean mass and litter size were recorded on different animals, or a common litter covariance, because the $c^{2}$ term was included only for lean mass. Bivariate analysis of body weight and litter size after generation 20 was not undertaken as computational demands were prohibitive, particularly because body weights were then taken on females and environmental covariances would have had to be included.

\section{Results}

\section{Analyses of body weight and composition to generation 20}

Mean body weights are shown in Fig. 1; it can be seen that substantial responses occurred, but only until about generation 33 in the high line. Responses for lean mass (to generation 20) are detailed by Beniwal et al. (1992). A summary of means at generation 20 is given in Table 1, and other details, including chemical body analysis, by Hastings \& Hill (1989). The responses in lean mass and body weight were similar; gonadal fat pad weight increased somewhat in the high line; and the ratio of gonadal fat pad weight to body weight increased in the low line.

Estimates of parameters are given in Table 2 based on data from all replicates of control lines together, and then from high with control and low with control to check whether selection had much effect. They were obtained using both bivariate REML analyses on each of body and fat weight and univariate REML analyses on body weight, fat pad weight and lean mass (as Beniwal et al., 1992, but without log transformation of data).

Estimates of $h^{2}$ and $c^{2}$ are approximately 0.5 and 0.25 , respectively, for all traits. Univariate and multivariate estimates agree well, no difference exceeding 1.5 per cent. The different datasets, which include all records to generation 20 with inferences back to the
Fig. 1 Generation means for 10-week body weight of males of each replicate, to generation 20 , and each line subsequently.

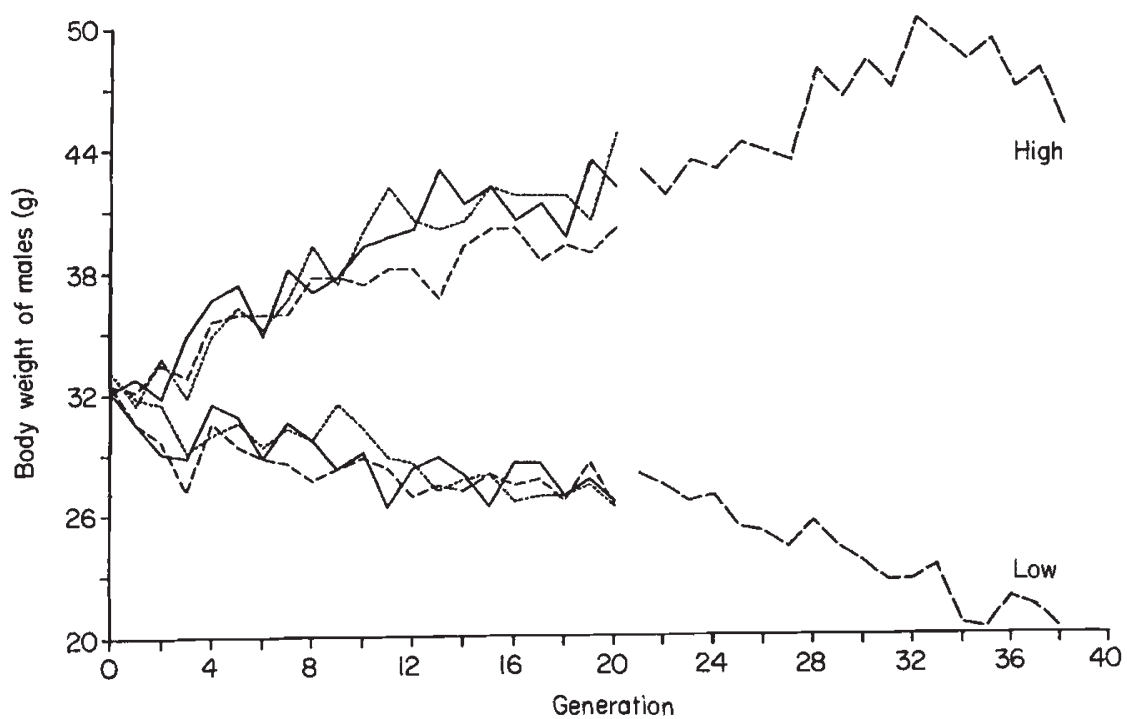

Table 1 Performance of lines averaged over replicates at generation 20

\begin{tabular}{|c|c|c|c|}
\hline \multirow[b]{2}{*}{ Traits } & \multicolumn{3}{|l|}{ Mean (SD) } \\
\hline & Low & Control & High \\
\hline Body weight $(\mathrm{g})$ & $26.5(2.02)$ & $30.5(2.67)$ & $42.4(4.26)$ \\
\hline Gonadal fat pad weight $(\mathrm{g})$ & $0.436(0.156)$ & $0.377(0.123)$ & $0.539(0.204)$ \\
\hline Predicted lean mass $(\mathrm{g})$ & $23.0(1.74)$ & $27.5(2.14)$ & $38.1(3.04)$ \\
\hline $\begin{array}{l}\left.\text { Fat ratio (mg g }{ }^{-1}\right) \\
\quad(\text { Fat pad weight/body weight })\end{array}$ & $16.3(5.23)$ & $12.2(3.16)$ & $12.5(3.43)$ \\
\hline
\end{tabular}


Table 2 Estimates of genetic parameters from multivariate $\left(r_{\mathrm{P}} / h^{2} / r_{\mathrm{A}}\right.$ and $\left.r_{\mathrm{E}} / c^{2} / r_{\mathrm{C}}\right)$ univariate $\left(h_{\mathrm{uni}}^{2}\right.$ and $\left.c_{\mathrm{uni}}^{2}\right)$ REML analyses for lean mass $(L M)$, body weight $(B W)$, gonadal fat pad weight $(F W)$ and the ratio of gonadal fat pad weight to body weight $(F P)$ in 10-week-old mice.*

\begin{tabular}{|c|c|c|c|c|c|c|c|c|c|c|}
\hline \multirow[b]{2}{*}{ Traits } & \multicolumn{4}{|c|}{$r_{\mathrm{P}} / h^{2} / r_{\mathrm{A}}(\times 100)^{*}$} & \multirow[b]{2}{*}{$h_{\mathrm{uni}}^{2}$} & \multicolumn{4}{|c|}{$r_{\mathrm{E}} / c^{2} / r_{\mathrm{C}}(\times 100)^{*}$} & \multirow[b]{2}{*}{$c_{\text {uni }}^{2}$} \\
\hline & $L M$ & $B W$ & $F W$ & $F P$ & & $L M$ & $B W$ & $F W$ & $F P$ & \\
\hline \multicolumn{11}{|l|}{ Control } \\
\hline$L M$ & $\underline{51.6}$ & 94.3 & 22.0 & -9.9 & 50.4 & 19.5 & 93.9 & 46.2 & 23.9 & 20.1 \\
\hline$B W$ & 93.4 & $\underline{50.3}$ & 53.1 & 23.7 & 51.1 & 92.1 & $\underline{24.8}$ & 73.9 & 55.8 & 24.5 \\
\hline$F W$ & 21.1 & 54.5 & 43.7 & - & 43.5 & -0.7 & 38.3 & $\underline{28.0}$ & - & 28.2 \\
\hline$F P$ & -8.3 & 27.8 & - & $\underline{43.6}$ & - & -28.9 & 10.6 & - & $\underline{24.3}$ & - \\
\hline \multicolumn{11}{|c|}{ Control + high } \\
\hline$L M$ & $\underline{48.5}$ & 93.2 & 18.3 & -10.0 & 50.0 & $\underline{23.4}$ & 95.5 & 49.5 & 24.2 & 24.0 \\
\hline$B W$ & 93.8 & 47.1 & 52.8 & 26.8 & 47.4 & 93.7 & $\underline{27.5}$ & 73.0 & 51.9 & 27.4 \\
\hline$F W$ & 24.2 & 56.4 & $\underline{50.4}$ & - & 50.3 & 12.0 & 45.9 & $\underline{25.0}$ & - & 25.1 \\
\hline$F P$ & -4.7 & 30.3 & - & $\underline{52.2}$ & - & -18.5 & 17.0 & - & $\underline{21.3}$ & - \\
\hline \multicolumn{11}{|c|}{ Control + low } \\
\hline$L M$ & $\underline{51.0}$ & 92.8 & 17.1 & -12.1 & 51.2 & $\underline{20.7}$ & 93.1 & 42.3 & 19.6 & 20.6 \\
\hline$B W$ & 92.1 & 48.4 & 52.6 & 25.7 & 48.3 & 90.3 & $\underline{25.3}$ & 72.3 & 53.9 & 25.4 \\
\hline$F W$ & 19.9 & 56.5 & 43.7 & - & 43.6 & 6.9 & 49.0 & $\underline{25.7}$ & - & 25.9 \\
\hline$F P$ & -7.2 & 32.3 & - & $\underline{44.6}$ & - & -18.7 & 25.2 & - & $\underline{22.8}$ & - \\
\hline
\end{tabular}

*Diagonals: heritability $\left(h^{2}\right)$, common litter $\left(c^{2}\right)$, above diagonal: genetic correlations $\left(r_{\mathrm{g}}\right)$, common litter correlations $\left(r_{\mathrm{c}}\right)$, below diagonal: phenotypic correlations $\left(r_{\mathrm{p}}\right)$, environmental correlations $\left(r_{\mathrm{e}}\right)$.

Table 3 Estimates of variance components and genetic parameters for 10-week body weight in $\mathrm{P}$ (replicates pooled) and P6 lines using log-transformed data. Analyses were carried out with homogeneous additive genetic and common litter variance assumptions*

\begin{tabular}{|c|c|c|c|c|c|c|}
\hline \multirow[b]{2}{*}{ Line } & \multicolumn{4}{|c|}{ Variance components $\left(\times 10^{-4}\right)$} & \multirow[b]{2}{*}{$h^{2}($ s.e $)$} & \multirow[b]{2}{*}{$c^{2}$ (s.e.) } \\
\hline & $V_{\mathrm{A}}$ & $V_{\mathrm{C}}$ & $V_{\mathrm{E}}$ & $V_{\mathrm{P}}$ & & \\
\hline \multicolumn{7}{|c|}{ P-lines (generations 0-20) } \\
\hline Overall & 52.3 & 27.3 & 26.5 & 106.1 & $0.493(0.024)$ & $0.257(0.015)$ \\
\hline Control & 55.5 & 26.4 & 27.5 & 109.4 & $0.507(0.073)$ & $0.242(0.028)$ \\
\hline High & 37.9 & 32.0 & 36.9 & 106.8 & $0.355(0.074)$ & $0.300(0.024)$ \\
\hline Low & 37.4 & 20.9 & 31.5 & 89.8 & $0.416(0.068)$ & $0.233(0.032)$ \\
\hline $\mathrm{C}+\mathrm{H}$ & 58.3 & 29.8 & 25.7 & 113.8 & $0.513(0.038)$ & $0.262(0.020)$ \\
\hline $\mathrm{C}+\mathrm{L}$ & 45.5 & 24.7 & 28.6 & 98.8 & $0.461(0.040)$ & $0.250(0.022)$ \\
\hline $\mathrm{H}+\mathrm{L}$ & 51.2 & 26.3 & 27.0 & 104.5 & $0.490(0.026)$ & $0.252(0.018)$ \\
\hline \multicolumn{7}{|c|}{ P6-lines (generations 21-38) } \\
\hline High & 17.0 & 37.8 & 48.6 & 103.4 & $0.164(0.103)$ & $0.366(0.053)$ \\
\hline Low & 35.1 & 16.6 & 41.7 & 93.4 & $0.376(0.074)$ & $0.178(0.032)$ \\
\hline$H+L$ & 36.7 & 28.1 & 41.2 & 106.0 & $0.346(0.029)$ & $0.265(0.023)$ \\
\hline
\end{tabular}

$\mathrm{C}=$ Control, $\mathrm{H}=$ High, $\mathrm{L}=$ Low.

*For P6: lines: number of records animals litters

$\begin{array}{llll}\text { High } & 1808 & 3205 & 237 \\ \text { Low } & 1576 & 2912 & 247 \\ \text { High + low } & 3384 & 6029 & 484\end{array}$


base population, give very similar estimates, even though some included the selected lines, as found previously for lean mass (Beniwal et al., 1992).

All correlations between $L M$ and $B W$ exceed 0.9. In general the genetic and phenotypic correlations for each pair of traits are similar but environment and litter correlations differ. Thus for $B W$ with $F W$, genetic and phenotypic correlations are just over 0.5 , whereas the environmental correlations within litters are rather smaller and those between litters are around 0.7 . The selection criterion, $L M$, has a genetic correlation of about 0.2 with $F W$ and -0.1 with $F R$, in accord with the observed small positive responses in the former and negative in the latter.

\section{Analysis of body weight to generation 38}

The above analyses were undertaken on untransformed data but, for those continuing to generation 38, $\log$ transformation was used because there were substantial differences in variance associated with differences in mean. Up to generation 20 , however, $h^{2}$ and $c^{2}$ estimates differed little between the two analyses (Table 2 cf. Table 3 ).

Using data only from generation 21 onwards but with full pedigrees fitted in the animal model back to generation 0 , estimates of base population parameters (Table 3) are smaller than estimates using earlier data, for example that for $h^{2}$ is 0.35 using high and low lines from generations 21-38, compared with 0.49 using earlier data, the latter being in accord with overall estimates. Values of $c^{2}$ tend to be higher in the high and low lines.

These changes were investigated further by assuming variance in high and low lines were heterogeneous and taking different periods of selection (Table 4). This analysis shows similar drops in heritability in both lines, but substantial differences in the $c^{2}$ term. The log-likelihood was 16.9 higher $(P<0.01)$ when variances were fitted for high and low separately than when $\mathrm{H}+\mathrm{L}$ were fitted together but separately for the first 20 and remaining 18 generations.

Selection responses, obtained using the mean predicted breeding values of all animals in each replicate each generation from the REML analyses with heterogeneous additive variance [see high (0-38) and low $(0-38)$ in Table 4] are given in Fig. 2. These show a similar pattern to the observed responses in Fig. 1. In Fig. 3 both observed mean divergence between high and low lines (Fig. 1) and that obtained from the REML predicted breeding values (Fig. 2) are compared directly. There is a strikingly good fit except in

Table 4 Estimates of variance components and genetic parameters for 10-week body weight. Analysis of high and low lines using log-transformed data and assuming homogeneous or heterogeneous additive genetic and common litter environment variances

\begin{tabular}{|c|c|c|c|c|c|c|}
\hline \multirow{2}{*}{$\begin{array}{l}\text { Group } \\
\text { description }\end{array}$} & \multicolumn{4}{|c|}{ Variance components $\left(\times 10^{-4}\right)$} & \multirow[b]{2}{*}{$h^{2}$} & \multirow[b]{2}{*}{$c^{2}$} \\
\hline & $V_{\mathrm{A}}$ & $V_{\mathrm{C}}$ & $V_{\mathrm{E}}$ & $V_{\mathrm{p}}$ & & \\
\hline \multicolumn{7}{|c|}{ P-lines (0-20 generations) } \\
\hline High & 57.7 & $30.3\}$ & \multirow{2}{*}{26.9} & $\int 114.9$ & 0.502 & 0.264 \\
\hline Low & 43.9 & 21.8 & & 92.6 & 0.474 & 0.235 \\
\hline \multicolumn{7}{|c|}{$P+P 6$ lines $(0-29$ generations $)$} \\
\hline High & 46.0 & $29.3\}$ & \multirow[t]{2}{*}{30.8} & $\int^{106.3}$ & 0.433 & 0.276 \\
\hline Low & 41.9 & $20.7\}$ & & 93.4 & 0.448 & 0.221 \\
\hline \multicolumn{7}{|c|}{$\mathrm{P}+\mathrm{P} 6$ lines $(0-38$ generations $)$} \\
\hline $\operatorname{High}(0-38)$ & 43.7 & 34.67 & \multirow{2}{*}{35.2} & $\int 113.5$ & 0.385 & 0.305 \\
\hline Low $(0-38)$ & 38.3 & 20.0 & & 93.5 & 0.409 & 0.214 \\
\hline$H+L(0-20)$ & 38.9 & 27.7 ? & \multirow{2}{*}{35.0} & $\int^{101.6}$ & 0.383 & 0.272 \\
\hline $\mathrm{H}+\mathrm{L}(21-38)$ & 45.1 & $25.1\}$ & & 105.2 & 0.429 & 0.238 \\
\hline \multicolumn{7}{|c|}{ P6-lines (21-38 generations) } \\
\hline $\operatorname{High}(21-38)$ & 35.7 & $37.8)$ & \multirow{2}{*}{41.3} & $\int^{114.8}$ & 0.311 & 0.329 \\
\hline Low $(21-38)$ & 37.5 & 18.7 & & 97.5 & 0.385 & 0.192 \\
\hline
\end{tabular}



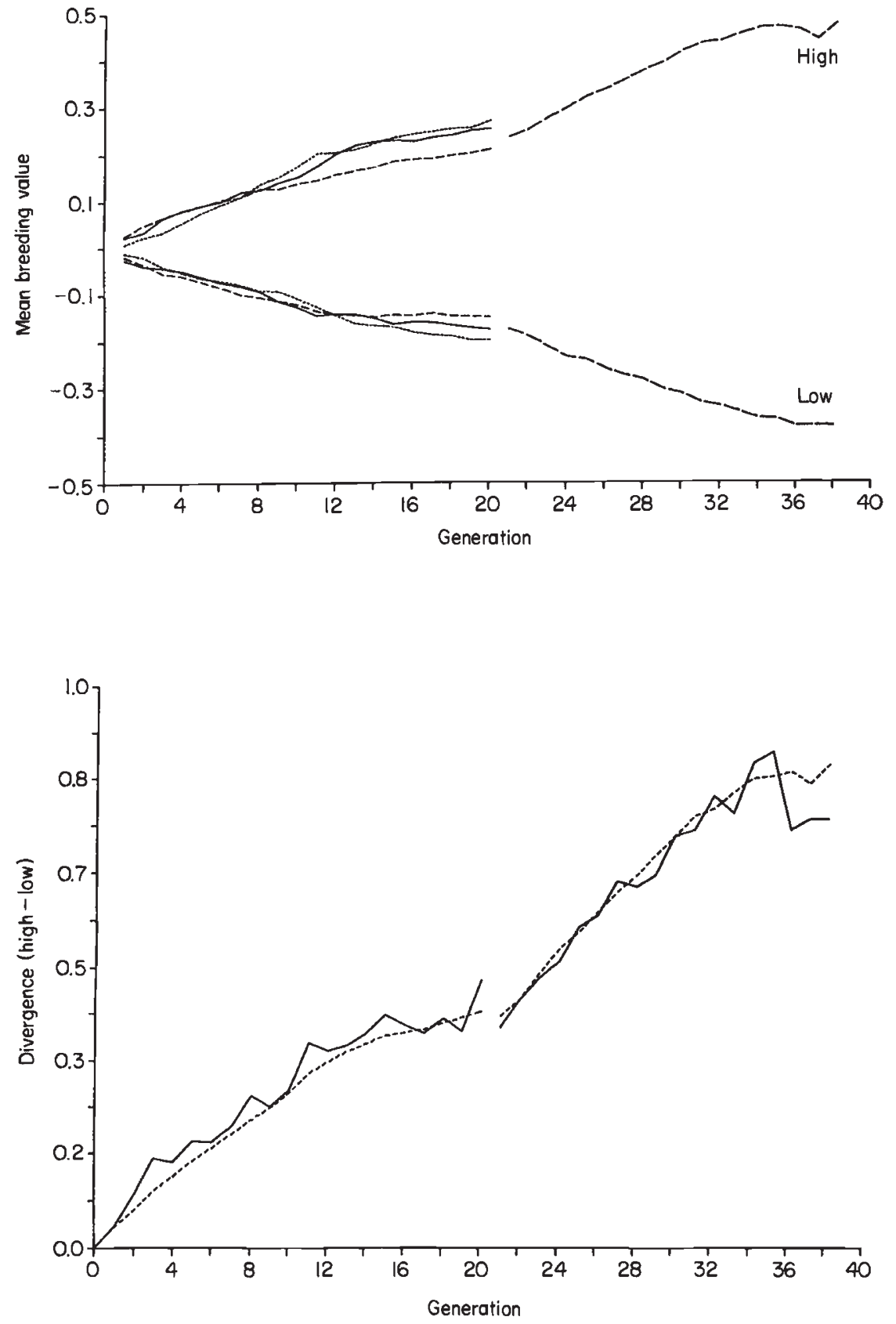

Fig. 2 Response to selection for 10week body weight (natural log units) using mean predicted breeding values of animals from the REML analysis assuming heterogeneity of $V_{\mathrm{A}}$ between high and low lines.

Fig. 3 Observed divergence $(-)$ and predicted (from REML) divergence (-- ) in 10-week body weight (natural log units) between high and low lines (replicates pooled to generation 20).

the last few generations, even though the estimates of heritability using the whole dataset differ from those based on only the first 20 generations. Whilst it is clear that the predictions for the high line alone and for the divergence indicate a tailing off of response, it was a little more drastic than predicted.

Selection differentials for each generation were examined (Fig. 4). These dropped in early generations in the low line, presumably through a reduction in variance due to a change in mean. There was a steady drop from about generation 30 in the low line and a rapid drop in the high line, associated with reduced litter size.

\section{Litter size}

The number of records of litter size and animals (i.e. including those without records represented through their pedigree) used in the analysis of generations 0-19 are given in Table 5. A clear positive correlated 
Fig. 4 Selection differentials for lean mass in generations $0-20$ for each replicate and subsequently for 10 -week body weight.

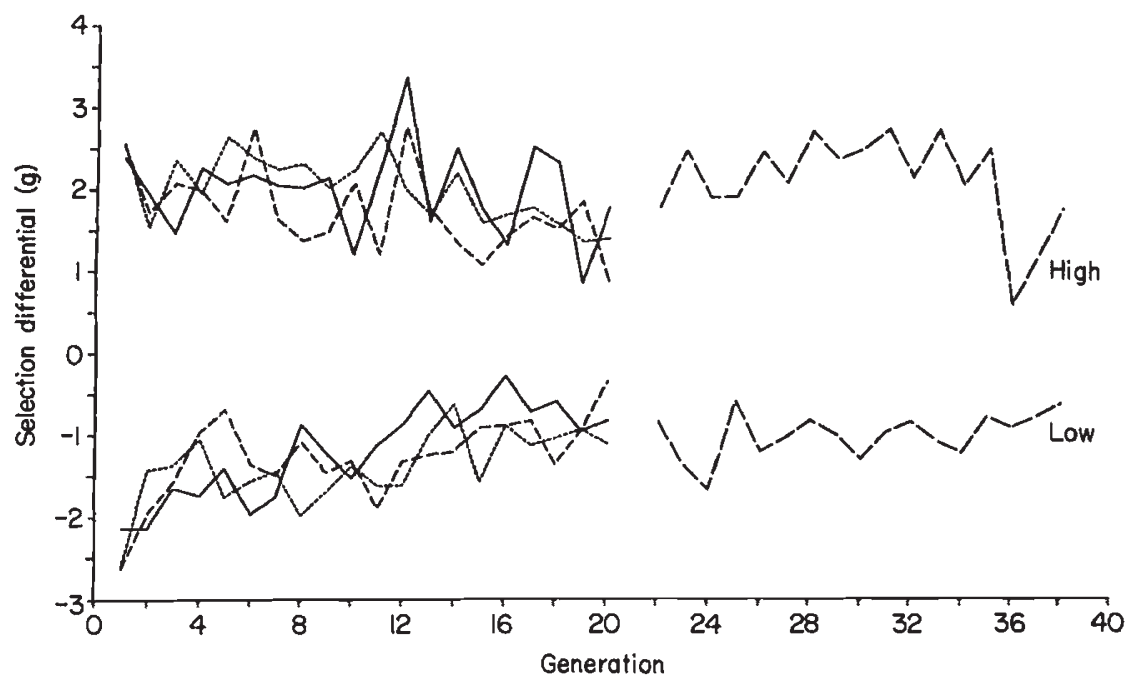

Table 5 Univariate estimates of genetic parameters for litter size in P-lines $(0-19$ generations)

\begin{tabular}{|c|c|c|c|c|c|c|}
\hline \multirow[b]{2}{*}{ Line/Rep. } & \multicolumn{2}{|c|}{ Number of } & \multirow[b]{2}{*}{$V_{\mathrm{A}}$} & \multirow[b]{2}{*}{$V_{\mathrm{E}}$} & \multirow[b]{2}{*}{$V_{\mathrm{P}}$} & \multirow[b]{2}{*}{$h^{2}($ s.e. $)$} \\
\hline & Records & Animals & & & & \\
\hline \multicolumn{7}{|c|}{ Homogeneous $V_{\mathrm{A}}$ and $V_{\mathrm{E}}$} \\
\hline Replicate 1 & 619 & 1300 & 1.23 & 4.45 & 5.68 & $0.217(0.026)$ \\
\hline Replicate 2 & 608 & 1273 & 0.38 & 4.51 & 4.88 & $0.077(0.089)$ \\
\hline Replicate 3 & 583 & 1210 & 0.86 & 5.15 & 6.01 & $0.144(0.081)$ \\
\hline Overall & 1810 & 3783 & 0.92 & 4.62 & 5.54 & $0.166(0.043)$ \\
\hline Control & 574 & 1277 & 1.00 & 4.53 & 5.53 & $0.181(0.093)$ \\
\hline High & 616 & 1349 & 0.29 & 5.42 & 5.71 & $0.051(0.081)$ \\
\hline Low & 620 & 1341 & $<0.001$ & 4.53 & 4.53 & $0.000(0.091)$ \\
\hline Control + High & 1190 & 2534 & 0.90 & 4.90 & 5.79 & $0.156(0.053)$ \\
\hline Control + Low & 1194 & 2526 & 0.47 & 4.63 & 5.10 & $0.093(0.061)$ \\
\hline High + Low & 1236 & 2602 & 0.91 & 4.52 & 5.43 & $0.168(0.048)$ \\
\hline \multicolumn{7}{|c|}{ Heterogeneous $V_{\mathrm{A}}$ and homogeneous $V_{\mathrm{E}}$} \\
\hline Control & \multicolumn{2}{|c|}{ As above } & 0.82 & \multirow{2}{*}{4.88} & $\int 5.69$ & 0.143 \\
\hline \multirow{2}{*}{ High } & \multicolumn{2}{|c|}{ Ros avove } & $1.06\}^{2}$ & & 5.93 & 0.178 \\
\hline & \multicolumn{6}{|c|}{ Control + low } \\
\hline Control & \multirow{2}{*}{\multicolumn{2}{|c|}{ As above }} & $1.07 ?$ & & $\int 5.59$ & 0.191 \\
\hline \multirow[b]{2}{*}{ Low } & & & & 52 & & \\
\hline & \multicolumn{6}{|c|}{$\begin{array}{c}<0.001) \\
\text { High + low }\end{array}$} \\
\hline High & \multirow{2}{*}{\multicolumn{2}{|c|}{ As above }} & 1.63 ? & \multirow{2}{*}{4.51} & 6.14 & 0.266 \\
\hline Low & & & $0.04\}$ & & 4.55 & 0.008 \\
\hline
\end{tabular}

response occurred in litter size to selection for lean mass over the first 20 generations (Fig. 5). There was a large increase in mean, particularly in the high line, after crossing the replicates, followed by continued correlated responses for 10 or so generations and then a subsequent drop in performance of the high line.

Univariate estimates of parameters for litter size up to generation 19 are presented in Table 5. The overall 


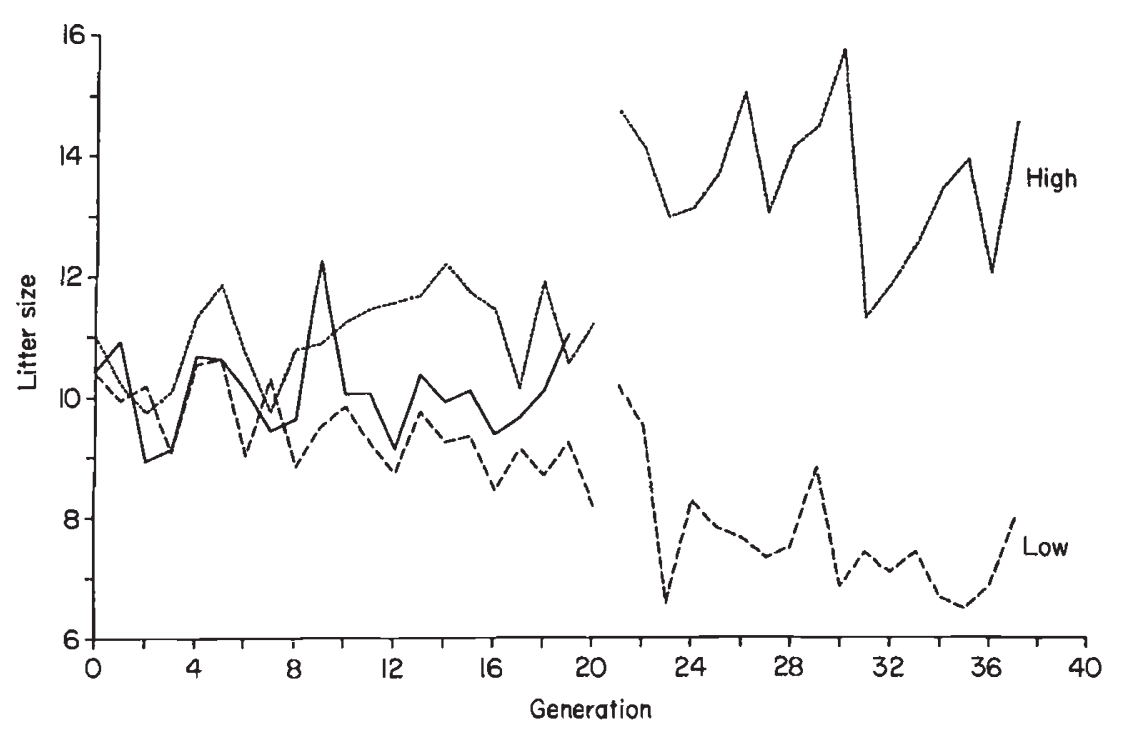

Fig. 5 Correlated responses in litter size (replicates pooled to generation 20). High $(\cdots \cdots)$, control ( $\longrightarrow$ ), low $(---)$. estimate of heritability is $0.17 \pm 0.04$, varying widely among replicates. These analyses were on untransformed data, but log transformation had a negligible effect on heritability estimates in these or other analyses of litter size. Although this estimate, based partly on data from selected lines, may be biased, it differs little from that obtained using control line data alone (0.18). Substantially different estimates are obtained from analyses of the selected lines taken alone or in pairs, with estimates of the heritability of litter size in the low line below 0.01 .

Bivariate analyses of lean mass and litter size (Table 6) for all lines combined to generation 20 gives a lower estimate $(0.10)$ of heritability of litter size than the

Table 6 Genetic parameters from bivariate and univariate analyses of predicted lean mass and litter size for control + high + low pooled P-lines data (0-19 generations)

\begin{tabular}{|c|c|c|c|c|}
\hline & \multicolumn{2}{|c|}{ Bivariate analysis } & \multicolumn{2}{|c|}{ Univariate analyses } \\
\hline & $\begin{array}{l}\text { Lean } \\
\text { mass }(\mathrm{g})\end{array}$ & $\begin{array}{l}\text { Litter } \\
\text { size }\end{array}$ & $\begin{array}{l}\text { Lean } \\
\text { mass }(\mathrm{g})\end{array}$ & $\begin{array}{l}\text { Litter } \\
\text { size }\end{array}$ \\
\hline$V_{\mathrm{A}}$ & 4.05 & 0.56 & 4.31 & 0.92 \\
\hline$V_{\mathrm{C}}$ & 2.32 & - & 1.91 & - \\
\hline$V_{\mathrm{E}}$ & 2.48 & 4.87 & 2.28 & 4.62 \\
\hline$V_{\mathrm{P}}$ & 8.86 & 5.44 & 8.50 & 5.54 \\
\hline$h^{2}$ (s.e.) & 0.458 & 0.103 & $0.507(0.021)$ & $0.166(0.043)$ \\
\hline$c^{2}$ (s.e.) & 0.263 & - & $0.225(0.015)$ & - \\
\hline $\begin{array}{l}\mathrm{Cov}_{\mathrm{A}} \\
\text { (genet) }\end{array}$ & $\begin{array}{l}0.412 \\
\text { tic covariance) }\end{array}$ & & - & - \\
\hline $\begin{array}{l}r_{\mathrm{A}}(\text { s.e. }) \\
\quad \text { (genet }\end{array}$ & $\begin{array}{c}0.273(0.100) \\
\text { tic covariance) }\end{array}$ & & - & - \\
\hline
\end{tabular}

corresponding univariate analyses, and the estimate for lean mass is also reduced. The estimate of genetic correlation between the two traits is 0.27 , with a 95 per cent confidence interval of $0.07-0.47$ (based on a reduction of 2.0 from its maximum in the log of the profile likelihood).

Data for litter size for the high and low lines up to generation 37 were analysed by univariate REML. Heritability estimates for the low line are consistently small, those for the high line sensitive to the method of analysis (Table 7). The lines had significantly heterogeneous variances. Assuming that best estimates in terms of efficiency and lack of bias due to heterogeneity come from analysing the lines together but with heterogeneous $V_{\mathrm{A}}$ and $V_{\mathrm{E}}$, the heritability of litter size has increased from the base value in the high line and reduced to near zero in the low line.

\section{Discussion}

The estimates of heritability and common environment correlations for the growth traits in males, namely body weight, fat pad weight and the lean mass and fat proportion indices, were very similar from univariate and multivariate analyses. As selection was on predicted lean mass, it was at first surprising that there was agreement for the other traits. The four traits has very similar heritabilities, however, and the genetic and phenotypic correlations for each pair of traits were nearly equal. This implies that with selection on trait 1 , the regression of breeding value on phenotype for correlated trait 2, i.e. $h_{1} h_{2} r_{\mathrm{A}} / r_{\mathrm{p}}$, is approximately equal to the heritability of trait 2 . The genetic and phenotypic regressions of trait 2 on trait 1 are the same and estimates based on indirect selection differentials and 
Table 7 Univariate estimates of parameters for litter size in P+P6-lines (0-37 generations)

\begin{tabular}{|c|c|c|c|c|c|c|c|}
\hline Lines & Records & Animals & $V_{\mathrm{A}}$ & $V_{\mathrm{E}}$ & $V_{\mathrm{P}}$ & $h^{2}$ (s.e.) & $L^{*}$ \\
\hline \multicolumn{8}{|c|}{ Lines analysed separately } \\
\hline High & 898 & 1920 & 0.207 & 7.325 & 7.532 & $0.028(0.065)$ & \\
\hline Low & 910 & 1910 & 0.001 & 4.200 & 4.201 & $0.000(0.084)$ & \\
\hline \multicolumn{8}{|l|}{ Lines pooled } \\
\hline \multicolumn{5}{|c|}{ Homogeneous $V_{\mathrm{A}}$ and $V_{\mathrm{E}}$} & 6.470 & $0.210(0.027)$ & 0.00 \\
\hline \multicolumn{8}{|c|}{ Heterogeneous $V_{\mathrm{A}}$ and homogeneous $V_{\mathrm{E}}$} \\
\hline High & & & $\left.\begin{array}{r}3.615 \\
<0.001\end{array}\right\}$ & 4.679 & $\left\{\begin{array}{l}8.293 \\
4.679\end{array}\right.$ & $\begin{array}{l}0.436 \\
0.000\end{array}$ & 29.35 \\
\hline \multicolumn{3}{|c|}{ Heterogeneous $V_{\mathrm{A}}$ and $V_{\mathrm{E}}$} & 2.2787 & 6.269 & 8.547 & 0.267 & \multirow{2}{*}{39.40} \\
\hline Low & & & $0.232)$ & 3.969 & 4.201 & 0.055 & \\
\hline
\end{tabular}

${ }^{*} L=\log$ likelihood as a deviation from fitting homogeneous variances.

response are therefore unbiased. (Note, in contrast, that multivariate and univariate estimates differed for litter size.) As a consequence, a univariate analysis of body weight over all 38 generations seems justified, even though it was not initially the directly selected trait.

The estimate of heritability of 10 -week body weight of approximately 0.5 is higher than a previous estimate for that trait (McCarthy \& Doolittle, 1977) and higher than most heritability estimates for body weight at earlier ages, typically 6 weeks (McCarthy, 1982). The estimate of 0.43 for the heritability of the ratio of gonadal fat pad to body weight $(F P)$ is the same as obtained by realized heritability for 11 generations for the $\mathrm{F}$ lines selected directly for this trait from the same base population and which showed large responses (Sharp et al., 1984; Hastings \& Hill, 1989). Although the estimate from the REML analysis of the genetic correlation between $F P$ and predicted leanness $(-0.10)$ differs in sign from that obtained $(0.12)$ as a realized genetic correlation (Sharp et al., 1984), both are small and accord with low correlations between lean mass and composition in other studies (Eisen, 1989). The lean mass index was constructed from phenotypic data and from the simple basis that oneeighth of the body fat was in the gonadal pads, and was intended to change body weight but not the proportion of fat. It is clear from the estimates and the results in Table 1 that this aim succeeded adequately, although partly because fat was somewhat over-corrected the selection criterion was changed to body weight after generation 20 .

Although the correlation pattern for $L M$ and $B W$ is similar for all components, this is not the case for $B W$ and $F P$, and thus for $L M$ and $F P$ as there is a substantial positive $c^{2}$ correlation between the traits. Presumably well nourished litters have bigger and fatter mice.

There is a change in the genetic variance and heritability of body weight as a result of selection, just as for lean mass with which it is highly correlated (Beniwal et al., 1992), even though inferences are made to the base population. In the model used to analyse P6 data after generation 20 , in which records of both males and females are included, it is assumed that there is no sex $\times$ genotype interaction. If, indeed, such an interaction is substantial, the estimates of heritability for each sex would be higher. Because selection was practised on both sexes a bivariate analysis would be necessary but involve substantial computation.

Although the genetic variance did appear to fall, the heritability of body weight was estimated at over 0.3 from generation 21 onwards; yet the high line appears to have reached a plateau soon after generation 30 . This suggests that natural selection is opposing artificial selection, there being further evidence that reductions in selection differentials in later generations were accompanied by even greater reductions in response. Relaxed selection lines have been established to investigate this further. Maximum likelihood methods need to be developed to enable examination of populations in plateau and lines drawn from them; for example a multivariate analysis incorporating traits of growth and reproduction could be useful although computationally demanding.

Note also that the litter environment $\left(c^{2}\right)$ correlation (confounded with non-additive genetic components) for 10 -week body weight changed, becoming higher in 
the high and low lines, both during the first 20 generations of selection for predicted lean mass at 10 weeks and subsequently with selection for body weight at that age. As there was a correlated increase in litter size in the high lines and mice were larger, presumably variation between dams, in resources such as milk production, would have more effect in the high than control than low lines. The $c^{2}$ term was large for such a high age, being 0.2 approximately at the start (Beniwal et al., 1992) and contributing nearly one-half of the full sib correlation. A contributing factor may have been that litter mates of the same sex were kept together after weaning when further competition may have occurred, particularly if the large mice were more crowded.

The positive correlated responses in litter size in the $\mathrm{P}$ and P6 lines were as expected from previous studies of correlated changes to selection for body weight in mice, and genetic changes in early generations were reported by Brien et al. (1984). In contrast, responses in the $\mathrm{F}$ lines, selected from the same base for fatness, have shown little change in reproductive performance (Brien et al., 1984; Hastings et al., 1991), confirming that responses were associated with body weight change. The correlated responses were very small after about generation 25 , however. The genetic covariance may have declined to zero, i.e. genes conferring the association became fixed, in accord with very small estimates of genetic variance in the low line. Inbreeding depression effects may have accumulated, with greater influence in the more variable high line. There may have been some consequence of natural selection in the high line, perhaps associated with reduced viability of large mice in large litters; because the proportion of mice born dead rose in the high line after generation 29 , averaging 9.5 per cent in generations 30-37 whereas it did not increase in the low line and averaged less than 2.5 per cent.

There was a substantial increase of about 2.7 in litter size following crossing the lines at generation 20. As expected from other studies (e.g. Roberts, 1960), heterosis is exhibited mainly in the generation when dams are crossbred, not in the previous generation when they are inbred but the young in their litters are crossbred. The value is greater than expected from Roberts' study, for example, but may not simply be due to heterosis as mice were older at mating in the $21 \mathrm{st}$ and subsequent generations than previously. There was a larger increase in the high than low line, perhaps through correlated responses to selection of parents and because of increased embryonic competition in the large high line litters, larger effects of inbreeding and heterosis on embryo survival.

The bivariate analysis of litter size and lean mass yielded different parameter estimates from the corre- sponding univariate analyses. This was not surprising for litter size because the univariate analysis is biased and ignores information derived from its correlation with the trait under selection. The change was not expected for lean mass, on which many more records than for litter size were included in the analysis, and on which selection had been practised. A possible explanation for how the estimates for lean mass could differ is that selection was practised in males and no records were taken on that trait in females, so litter size itself provided information, albeit tenuous, on the lean mass of the females sampled as parents. Litter size at birth was fitted in the bivariate analysis as a covariate for lean mass but not for litter size; this may have biased estimates of parameters for litter size but not lean mass. The estimate of the genetic correlation between litter size and lean mass of 0.27 is close to a realized estimate of 0.24 using correlated responses alone (calculations not shown); whilst the former could be biased by $c^{2}$ effects common to litter mates, the latter is not.

This study illustrates the power and versatility of the maximum likelihood methods. Thus estimates of genetic parameters such as correlations of traits which were not themselves under selection, for example litter size and the proportion of fat depots, could be obtained for lines selected for another trait, and sampling errors could be estimated from unreplicated lines, for example after generation 20 . This could be very useful for traits recorded only after lines have long been established, for example physiological variables which may have shown a correlated response but which are expensive to determine. In view of the labour involved in maintaining selection experiments, it is worthwhile undertaking efficient statistical analysis.

\section{Acknowledgements}

This work was supported by a grant from the Agricultural and Food Research Council. BKB was in receipt of a Commonwealth Scholarship. We are grateful to Douglas Falconer and an anonymous referee for helpful comments.

\section{References}

BENIWAL, B. K., HASTINGS, I. M., THOMPSON, R. AND HILL, W. G. 1992. Estimation of changes in genetic parameters in selected lines of mice using REML with an animal model. 1. Lean mass. Heredity, 69, 352-360.

BRIEN, F. D., SHARP, G. L., HILL, W. G. AND ROBERTSON, A. 1984. Effects of selection on growth, body composition and food intake and mice. II. Correlated responses in reproduction. Genet. Res., 44, 73-85. 
EISEN, E. J. 1989. Selection experiments for body composition in mice and rats: A review. Livest. Prod. Sci., 23, 17-32.

HASTINGS, I. M. AND HILL, W. G. 1989. A note on the effect of different selection criteria on carcass composition in mice. Anim. Prod., 48, 229-233.

HASTINGS, I. M., YANG, J. AND HILL, W. G. 1991. Analysis of lines of mice selected on fat content. 4. Correlated responses in growth and reproduction. Genet. Res. 58, 253-259.

McCARTHY, J. C. 1982. The laboratory mouse as a model for animal breeding. A review of selection for increased body weight and litter size. Proc. 2nd World Congr. Genet. Appl. Livest. Prod., Madrid, 5, 66-83.

McCARTHY, J. C. AND DOOLITTLE, D. P. 1977. Effect of selection for independent changes in two highly correlated body weight traits of mice. Genet. Res., 29, 133-145.

MEYER, K. 1988. DFREML-Programs to estimate variance components for individual animal models by Restricted Maximum Likelihood (REML). User Notes. Institute of Animal Genetics, University of Edinburgh, Edinburgh, U.K.
MEYER, K. AND THOMPSON, R. 1984. Bias in variance and covariance component estimators due to selection on a correlated trait. Z. Tierz. Zuchtbiol. 101, 33-50.

ROBERTS, R. C. 1960. The effects on litter size of crossing lines of mice inbred without selection. Genet. Res., 1, 239-252.

SHARP, G. L., HILL, W. G. AND ROBERTSON, A. 1984. Effects of selection on growth, body composition and food intake in mice. I. Responses in selected traits. Genet. Res., 43, 75-92.

THOMPSON, R. AND HILL, w. G. 1990. Univariate REML analyses for multivariate data with the animal model. Proc. 4 th World Congr. Genet. Appl. Livest. Prod., Edinburgh, 12, 484-487.

VISSCHER, P. AND THOMPSON, R. 1990. REML estimates of parameters for fat yield in pedigree herds in the U.K. using an individual animal model: Male and female heritability esimates. Proc. 4th World Congr. Genet. Appl. Livest. Prod., Edinburgh, 14, 484-487. 